\title{
Incidence of delayed cerebral ischaemia following subarachnoid haemorrhage of unknown cause
}

\author{
PHILIP BARLOW \\ From the Institute of Neurological Sciences, Southern General Hospital, Glasgow, UK
}

SUMMARY A retrospective study was made of 50 consecutive patients with spontaneous subarachnoid haemorrhage for which no cause was found, looking for evidence of delayed cerebral ischaemia particularly during the first 2 weeks after the bleed. Twenty-three patients had blood visible on the CT scan but only 4-6\% developed delayed ischaemia, all of whom made a good recovery. The low incidence of this complication in this group of patients suggests that subarachnoid blood is not a sufficient cause for delayed ischaemia.

Following subarachnoid haemorrhage from a ruptured aneurysm delayed cerebral ischaemia is a common and dangerous complication. It is recognised by a decrease in conscious level and/or the appearance of focal neurological signs, with no evidence of recurrent haemorrhage. Almost all cases occur within two weeks of the initial bleed. ${ }^{2}$ In studies where care has been taken to distinguish delayed ischaemia from early rebleeding or other complications the incidence varies from $25-42 \%$, depending upon the timing of surgery, extent of removal of subarachnoid blood, and the use of anti-fibrinolytic drugs (table 1).

Despite its common occurrence the aetiology of delayed cerebral ischaemia is unknown. There is an association with cerebral arterial vasospasm, ${ }^{6-10}$ but the relationship is not clear. ${ }^{112}$ Blood and blood products within the subarachnoid space have been implicated in causing vasospasm and ischaemia, and this has led some surgeons to attempt radical removal of all subarachnoid blood at operation. ${ }^{413}$

In order to examine this suggestion, that blood within the subarachnoid space causes delayed cerebral ischaemia, a group of patients with proven spontaneous subarachnoid haemorrhage was studied in whom no aneurysm or arterio-venous malformation was shown on angiography.

\section{Method}

The case notes of all patients with subarachnoid haemor-

Address for reprint requests: Mr P Barlow, Institute of Neurological Sciences, Southern General Hospital, Glasgow G51 4TF, UK.

Received 10 April 1984 and in revised form 19 July 1984. Accepted 21 July 1984
Table 1 Incidence of delayed ischaemia following a ruptured aneurysm

\begin{tabular}{|c|c|c|}
\hline & $\begin{array}{l}\text { Total incidence } \\
\text { of delayed } \\
\text { ischaemia }\end{array}$ & $\begin{array}{l}\text { Delayed ischaemia } \\
\text { causing permanent } \\
\text { deficit, infarct } \\
\text { or death }\end{array}$ \\
\hline $\begin{array}{l}\text { Maurice-Williams, } 1982^{1} \\
\text { Bolander et al, } 1984^{3}\end{array}$ & $33 \%$ & $13 \%$ \\
\hline $\begin{array}{l}\text { early operation } \\
\text { late operation }\end{array}$ & $\begin{array}{l}42 \% \\
25 \%\end{array}$ & $31 \%$ \\
\hline $\begin{array}{l}\text { Taneda, } 1982^{4} \\
\text { limited blood removal } \\
\text { radical blood removal }\end{array}$ & $\begin{array}{l}40 \% \\
30 \%\end{array}$ & $\begin{array}{l}28 \% \\
11 \%\end{array}$ \\
\hline $\begin{array}{l}\text { Vermeulen et al, } 1984^{5} \\
\text { antifibrinolytics } \\
\text { no antifibrinolytics }\end{array}$ & - & $\begin{array}{l}28 \% \\
12 \%\end{array}$ \\
\hline
\end{tabular}

rhage of unknown cause who were investigated at the Institute of Neurological Sciences, Glasgow during 1981-82 were reviewed. Patients were admitted to the study if they fulfilled the following criteria: (1) A history of spontaneous subarachnoid haemorrhage; (2) A CT scan performed; (3) Subarachnoid haemorrhage confirmed by lumbar puncture and/or blood on CT scan; (4) Bilateral carotid and vertebral angiogram failed to show a cause for the haemorrhage.

Patients with a head injury or primary intracerebral haematoma were excluded, but cases of intraventricular haemorrhage were included. One patient was excluded because a CT scan was not performed. The case records were examined for the whole time spent in hospital, paying particular attention to evidence of neurological deterioration in the two weeks following the haemorrhage Neurological deterioration was defined as a decrease in conscious level, the appearance of focal signs, or both. The clinical grade was assessed on admission to the neurosurgical unit according to Hunt and Hess, ${ }^{14}$ but unmodified by systemic disease.

Seventeen patients were discharged home before two weeks by which time all were alert and orientated with no 
Table 2 Age and sex distribution of 50 patients with subarachnoid haemorrhage of unknown cause

\begin{tabular}{lcc}
\hline Age $(y r)$ & Male & Female \\
\hline $20-29$ & 3 & 1 \\
$30-39$ & 3 & 3 \\
$40-49$ & 5 & 3 \\
$50-59$ & 7 & 15 \\
$60-69$ & 3 & 7 \\
Total & 21 & 29 \\
\hline
\end{tabular}

Table 3 Clinical details

\begin{tabular}{lllllllll}
\hline Number & $\begin{array}{l}\text { Hunt \& Hess grade } \\
\text { (unmodified) }\end{array}$ & & $\begin{array}{l}\text { Initial } \\
\text { Coma }\end{array}$ & Hypertension \\
\cline { 2 - 7 } & $I$ & II & III & IV & V & & \\
\hline 50 & 4 & 33 & 11 & 2 & 0 & 7 & 10 \\
\hline
\end{tabular}

neurological signs. Sixteen of these were assessed later at an out-patient clinic. Direct contact was made with the seventeenth patient and his general practitioner by telephone.

\section{Results}

Between the years $1981-82$ there were 50 patients who fulfilled the criteria. Their ages ranged from 20-64 years with a mean of $49 \cdot 2 \pm 13 \cdot 2 \mathrm{SD}$. Females were more common than males, particularly in the older age group (table 2). Table 3 shows the clinical grade on admission to the Neurosurgical Unit, the occurrence of coma at the time of the bleed, and the presence of hypertension (defined as taking anti-hypertensive drugs and/or blood pressure over $160 / 90 \mathrm{~mm} \mathrm{Hg}$ on admission). Of the seven patients who were in coma only two remained in coma for more than 24 hours; these are the only two patients who were Grade IV on admission.

A CT scan was done in 32 patients within three days of their bleed, on 16 within seven days, and on the remaining two patients after the first week. Blood was visible on the scan in 23 patients, the most common site being within the basal cisterns (table 4). Eleven patients had blood at more than one of the main sites.

Bilateral carotid and vertebral angiography was carried out in all patients, but in four cases, for technical reasons, one of the posterior inferior cerebellar arteries could not be visualised. In another four patients angiography was repeated because arterial vasospasm made exclusion of an aneurysm difficult.
Table 5 Delayed deterioration in fine patients

\begin{tabular}{|c|c|c|}
\hline Patient & Nature of deterioration & Blood on CT scan \\
\hline $\begin{array}{l}1 \\
2 \\
3 \\
4\end{array}$ & $\begin{array}{l}\text { Died-cardiac failure } \\
\text { Died-rebleed } \\
\text { Transient confusion } \\
\text { Transient left arm } \\
\text { weakness }\end{array}$ & $\begin{array}{l}\text { Ventricles } \\
\text { Interfrontal, basal cisterns } \\
\text { Ventricles } \\
\text { No }\end{array}$ \\
\hline 5 & $\begin{array}{l}\text { Dysphasia and rt } \\
\text { hemiparesis }\end{array}$ & $\begin{array}{l}\text { Basal cisterns, interfrontal, } \\
\text { and left Sylvian fissure }\end{array}$ \\
\hline
\end{tabular}

\section{Deterioration}

Five patients deteriorated within two weeks of the initial bleed. Two of the five died, two recovered completely, but the fifth developed a fixed deficit (table 5).

Patient 1. A 50-year-old hypertensive lady with kyphoscoliosis was admitted four days after sudden onset of headache, neck stiffness and confusion. She remained confused and on admission had a mild left hemiparesis. CT scan showed intraventricular blood but four vessel angiogram was normal. Her neurological condition remained unchanged until three days after admission when she deteriorated over a few hours. Examination showed a severe chest infection, cardiac failure and hypotension. She died several hours later despite treatment, and a post-mortem examination confirmed intraventricular haemorrhage, cardiac failure and acute bronchitis. There were also cerbral and cerebellar boundary zone infarcts consistent with a period of profound hypotension. The site of bleeding was a small area of haemorrhagic necrosis in the posterior part of the interventricular septum. There was no evidence of tumour. This lady's deterioration was most likely due to a chest infection and cardiac failure leading to secondary hypotension and boundary zone infarcts.

Patient 2. A 57-year-old female was admitted on the day of the haemorrhage. She was slightly confused but recovered completely within 24 hours; she had no focal signs. CT scan showed blood in the interhemispheric fissure and ambient cistern but the angiogram was normal. She was discharged back to the referring hospital where she remained well for three days, then suddenly deteriorated. Lumbar puncture showed uniformly blood stained fluid and a diagnosis of rebleed was made (eight days from the first bleed). She was not referred back and died two days later. No post-mortem examination was per-

Table 4 Distribution of blood on CT scan

\begin{tabular}{lllll}
\hline Number & Interfrontal & Basal cisterns & $\begin{array}{l}\text { Right or left } \\
\text { Sylvian fissure }\end{array}$ & Ventricles \\
\hline 23 & 6 & 15 & 5 & 8 \\
\hline
\end{tabular}


formed. Presumably the patient had an aneurysm that failed to show on the angiogram.

Patient 3. A 64-year-old woman with ulcerative colitis and hypertension was alert and orientated with no focal signs on admission; CT scan showed intraventricular blood. Immediately following recovery from four vessel angiography performed under general anaesthetic (three days from the bleed) she was confused but had no focal signs. Her confusion resolved within 48 hours and she remained well until discharge. Her deterioration was probably due to the combined effect of cerebral angiography and a general anaesthetic, but delayed cerebral ischaemia cannot be ruled out as a possible cause.

Patient 4. A 20-year-old man was fully alert and orientated on admission, with no focal signs, but complaining of headache and neck stiffness. CT scan and four vessel angiogram were normal, with no subarachnoid blood or vasospasm. Thirty-six hours following angiography (4 days from the bleed) he developed a mild left arm weakness but remained alert. The weakness resolved within several days and he was discharged home. At out-patient follow up he remained completely well. Although his deficit was mild and he remained alert, the deterioration was probably due to delayed ischaemia. No other cause was apparent for the left monoparesis.

Patient 5. This patient showed the clinical picture usually associated with significant delayed cerebral ischaemia. She was a 48-year-old previously well woman, in whom there was a sudden onset of frontal headache, neck stiffness and vomiting but no loss of consciousness. On admission the day after the bleed she was orientated with no focal signs but complained of headache and neck stiffness. CT scan showed subarachnoid blood in the basal cisterns, interfrontal region and left Sylvian fissure. Four vessel angiography was normal (no vasospasm). Seven days after the haemorrhage her conscious level deteriorated and she became dysphasic with a mild right hemiparesis. A repeat CT scan showed a possible area of low density in the left temporal region. Her blood pressure was normal throughout the ill- ness. No further action was taken and her condition improved spontaneously over the following two weeks. She was discharged home at four weeks from the bleed, fully mobile and independent, but with a mild residual dysphasia.

Of the five patients who deteriorated, delayed cerebral ischaemia probably was the cause in two (patients 4 and 5), and possibly a third (patient 3 )-an incidence of 4-6\%. Of the two likely cases of delayed cerebral ischaemia one had blood on the CT scan and one did not. Nineteen patients had blood on the CT scan and did not deteriorate.

\section{Discussion}

Previous reports have shown that the prognosis of patients with subarachnoid haemorrhage for which no cause is found, both in the short and long term, is better than in those with subarachnoid haemorrhage due to an aneurysm; in particular the rebleed rate is low (table 6).

The principal aim of previous studies was to ascertain the prognosis; the incidence of delayed deterioration was discussed only briefly, if at all. Some early studies would in any event have been unsuitable for identifying cases of delayed ischaemia. The CT scan was not available to exclude primary intracerebrap haematoma, and vertebral angiography was nok routine; a number of the cases must have deterio 0 T rated due to rebleeding from posterior circulation aneurysms.

The three most recent reports ${ }^{20-22}$ all comment on the incidence of delayed deterioration but their series cannot be compared to the present study. Hayward ${ }^{20}$ reported three cases of transient deterioration, but included in his study head injured patients and two patients with intracerebral haematomas; only four patients had blood on the CT scan compared with 23 in this study. Sundbärg et al, ${ }^{21}$ reported 128 patients with subarachnoid haemorrhage of unknown cause and stated that 11 had delayed cerebral ischaemia; seven of these died or were permanently disabled. Their series started in 1968 and it is therefore not possible to correlate

Table 6 Prognosis following subarachnoid haemorrhage of unknown cause

\begin{tabular}{|c|c|c|c|c|}
\hline Author & Number of patients & $\underset{(y r)}{\text { Length of follow-up }}$ & Total mortality & Rebleed rate \\
\hline $\begin{array}{l}\text { Walsh, } 1956^{15} \\
\text { Dunsmore, } 1956^{16} \\
\text { af Björkesten, } 1957^{17} \\
\text { Höök, } 1958^{18} \\
\text { Levy, 1960'19 } \\
\text { Hayward, } 1977^{20} \\
\text { Sundbärg, } 1982^{21} \\
\text { Béguelin, } 1983^{22}\end{array}$ & $\begin{array}{r}93 \\
81 \\
61 \\
138 \\
76 \\
51 \\
128 \\
42\end{array}$ & $\begin{array}{l}2-15 \\
1-10 \\
1-8 \\
1-10 \\
1-8 \\
1-3 \\
3-13 \\
1-5\end{array}$ & $\begin{array}{l}16 \% \\
27 \% \\
5 \% \\
11 \cdot 5 \% \\
10 \cdot 5 \% \\
0 \\
4 \% \\
12 \%\end{array}$ & $\begin{array}{l}12 \% \\
21 \% \\
8 \% \\
7 \% \\
1 \cdot 5 \% \\
0 \\
3 \% \\
2 \%\end{array}$ \\
\hline
\end{tabular}


these results with the CT scan findings, or to exclude primary intracerebral haematomas. The study of Béguelin and Seiler ${ }^{22}$ is also inadequate. Of 42 patients five died from "ischaemic complications". All five were receiving anti-fibrinolytic drugs, which are known to increase the incidence of cerebral ischaemia, ${ }^{523}$ and three of the five did not have a CT scan. The post mortem findings were not reported, and the causes of death are therefore uncertain.

The present study described 50 patients with proven subarachnoid haemorrhage not related to head injury or intracerebral haematoma. Fifteen patients had blood visible within the basal cisterns, which in aneurysmal subarachnoid haemorrhage is consistently associated with a high incidence of vasospasm and delayed cerebral ischaemia. ${ }^{8-1024-26}$ Two patients had a mild transient neurological deterioration, and in one case (patient 3 ) this was most likely due to the general anaesthetic and angiography as it occurred only three days following the bleed. Only one patient developed a fixed deficit, and even her eventual outcome was satisfactory.

The incidence of delayed ischaemia in our group of patients $(4-6 \%)$ is lower than that with subarachnoid haemorrhage caused by an aneurysm (25$42 \%$ ). This suggests that the mere presence of blood in the subarachnoid space is not sufficient cause for delayed ischaemia. There may therefore be other factors, specific to patients who have an aneurysm, that predispose to the development of ischaemia.

Smith et $\mathbf{l}^{27}$ showed that severe vasospasm and an associated angiopathy are related to haemorrhage within the wall of the affected intracranial artery; they found that blood around the arteries had little effect. As most aneurysms are situated on major intracranial vessels, rupture of an aneurysm may lead to intramural haemorrhage. In cases of subarachnoid haemorrhage with normal angiograms the bleed may be from small vessels or tiny angiomas, ${ }^{28}$ and intramural haemorrhage within a large vessel would not occur. This mechanism could explain the case of Friedman et al, where there was arterial vasospasm (accompanied by neurological deterioration) in association with an aneurysm that had not ruptured but probably enlarged. ${ }^{29}$

There may also be genetic differences between patients who have an aneurysm and those who do not. $^{30-32}$ If so, then there may be inherent abnormalities in the arteries of patients with aneurysms that also predispose to the development of spasm.

Whatever the mechanism the outlook for these patients is good, provided they survive the initial effect of the haemorrhage. The incidence of rebleeding and of delayed ischaemia is low and most patients can therefore be mobilised early (in this study 17 patients returned home within two weeks, and a further 20 within three weeks). Even the two or three patients who developed delayed ischaemia all made a good recovery, and no patient showed the fulminant picture of massive infarction and death seen so commonly after subarachnoid haemorrhage from an aneurysm.

I am very grateful to Dr E Teasdale and Dr P Macpherson for reviewing the radiographs.

\section{References}

${ }^{1}$ Maurice-Williams, RS. Ruptured intracranial aneurysms: has the incidence of early re-bleeding been over-estimated. J Neurol Neurosurg Psychiatry 1982; 45:774-9.

${ }^{2}$ Mohan J. The neurosurgeon's view. Clinical aspects of cerebral arterial spasm. In: Boullin DJ, ed. Cerebral Vasospasm. Chichester: John Wiley and Sons, 1980:15-35.

${ }^{3}$ Bolander HG, Kourtopoulos H, West KA. Retrospective analysis of 162 consecutive cases of ruptured intracranial aneurysms. Total mortality and early surgery. Acta Neurochir 1984;70:31-41.

${ }^{4}$ Taneda M. Effect of early operation for ruptured aneurysms on prevention of delayed ischaemic symptoms. $J$ Neurosurg 1982;57:622-8.

${ }^{5}$ Vermeulen M, Lindsay KW, Murray GD, et al. Antifibrinolytic treatment in subarachnoid hemorrhage. A multicentre double-blind, placebo-controlled trial. New Engl J Med 1984 (in press).

- Graham DI, Macpherson P, Pitts LH. Correlation between angiographic vasospasm, hematoma, and ischemic brain damage following subarachnoid hemorrhage. J Neurosurg 1983;59:223-30.

${ }^{7}$ Fisher CM, Robertson GH, Ojemann RG. Cerebral vasospasm with ruptured saccular aneurysm-the clinical manifestations. Neurosurgery 1977;1:245-8.

${ }^{8}$ Sarto I, Shigeno T, Arikake K, et al . Vasospasm assessed by angiography and computerised tomography. $J$ Neurosurg 1979;51:466-75.

${ }^{9}$ Fisher CM, Kistler JP, Davis JM. Relation of cerebral vasospasm to subarachnoid hemorrhage visualised by computerised. tomographic scanning. Neurosurgery 1980;6:1-9.

${ }^{10}$ Suzuki J, Komatsu S, Sato T, Sakurai Y. Correlation between CT findings and subsequent development of cerebral infarction due to vasospasm in subarachnoid haemorrhage. Acta Neurochir 1980;55:63-70.

"Millikan $\mathrm{CH}$. Cerebral vasospasm and ruptured intracranial aneurysm. Arch Neurol 1975;32:433-49.

${ }^{12}$ Ljungrenm B, Brandt L, Kågström E, Sundbärg G. Results of early operation for ruptured aneurysms. $J$ Neurosurg 1981;54:473-9.

${ }^{13}$ Mizukami M, Kawase T, Usami T, Tazawa T. Prevention of vasospasm by early operation with removal of subarachnoid blood. Neurosurgery 1982;10:301-7.

${ }^{14}$ Hunt WE, Hess RM. Surgical risk as related to time of intervention in the repair of intracranial aneurysm. $J$ Neurosurg 1968;28:14-20. 
is Walsh LS. Subarachnoid hemorrhage. Acta Radiologica 1956;46:321-5.

${ }^{16}$ Dunsmore RH, Polcyn JL. Subarachnoid hemorrhage: prognostic factors. J Neurosurg 1956;13:165-9.

${ }^{17}$ af Björkesten G, Troupp H. Prognosis of subarachnoid hemorrhage. A comparison between patients with verified aneurysms and patients with normal angiograms. J Neurosurg 1957; 14:434-41.

${ }^{18}$ Höök O. Subarachnoid haemorrhage. Prognosis when angiography reveals no aneurysm. A report of 138 cases. Acta Med Scandinav 1958;162:493-503.

${ }^{19}$ Levy LF. Subarachnoid haemorrhage without arteriographic vascular abnormality. J Neurosurg 1960; 17:252-8.

${ }^{20}$ Hayward RD. Subarachnoid haemorrhage of unknown aetiology: a clinical and radiological study of 51 cases. J Neurol Neurosurg Psychiatry 1977;40:926-31.

${ }^{21}$ Sundbärg G, Brismar J, Ljunggren B. Subarachnoid haemorrhage of unknown origin-a good natured catastrophe. Acta Neurochir 1982;66:251.

${ }^{22}$ Béguelin C, Seiler R. Subarachnoid hemorrhage with normal cerebral panangiography. Neurosurgery 1983; 13:409-11.

${ }^{23}$ Fodstad H, Forsell $\AA$, Liliequist B, Schannong M. Antifibrinolytics with tranexamic acid in aneurysmal subarachnoid hemorrhage. A consecutive controlled clinical trial. Neurosurgery 1981;8:158-65.

${ }^{24}$ Kistler JP, Growel RM, Davis KR, et al. The relation of cerebral vasospasm to the extent and location of subarachnoid blood visualised by CT scan: a prospective study. Neurosurgery 1983;33:424-36.

${ }^{25}$ Mizukami M, Takemae T, Tazawa T, Kawase T, Matsazuki $T$. Value of computed tomography in the prediction of cerebral vasospasm after aneurysm rupture. Neurosurgery 1980; 7:583-6.

${ }^{26}$ Pasqualin A, Rosta L, Scienza R. Prediction of vasospasm in patients with subarachnoid haemorrhage: the role of the CT scan. J Chron Dis Thor Res 1983; 7:16.

${ }^{27}$ Smith RR, Clower BR, Peeler DF, Yoshioka J. The angiopathy of subarachnoid haemorrhage: angiographic and morphologic correlates. Stroke $1983 ; 14: 240-5$.

${ }^{28}$ Hyland $\mathrm{HH}$. Non-aneurysmal intracranial hemorrhage. Neurology (Minneap) 1961;11(2):165-8.

${ }^{29}$ Friedman P, Gass H, Magidson M. Vasospasm with an unruptured unoperated aneurysm. Surg Neurol 1983;19:21-5.

${ }^{30}$ Neil-Dwyer G, Bartlett JR, Nicholls AC, Marcisi P, Pope FM. Collagen deficiency and ruptured cerebral artery aneurysms. J Neurosurg 1983;59:16-20.

${ }^{31}$ Kristensen MO. Increased incidence of bleeding intracranial aneurysms in Greenlandic Esquimos. Acta Neurochir 1983;67:37-43.

${ }^{32}$ Fox JL. Familial intracranial aneurysms: case report. Neurosurg 1982;57:416-7. 